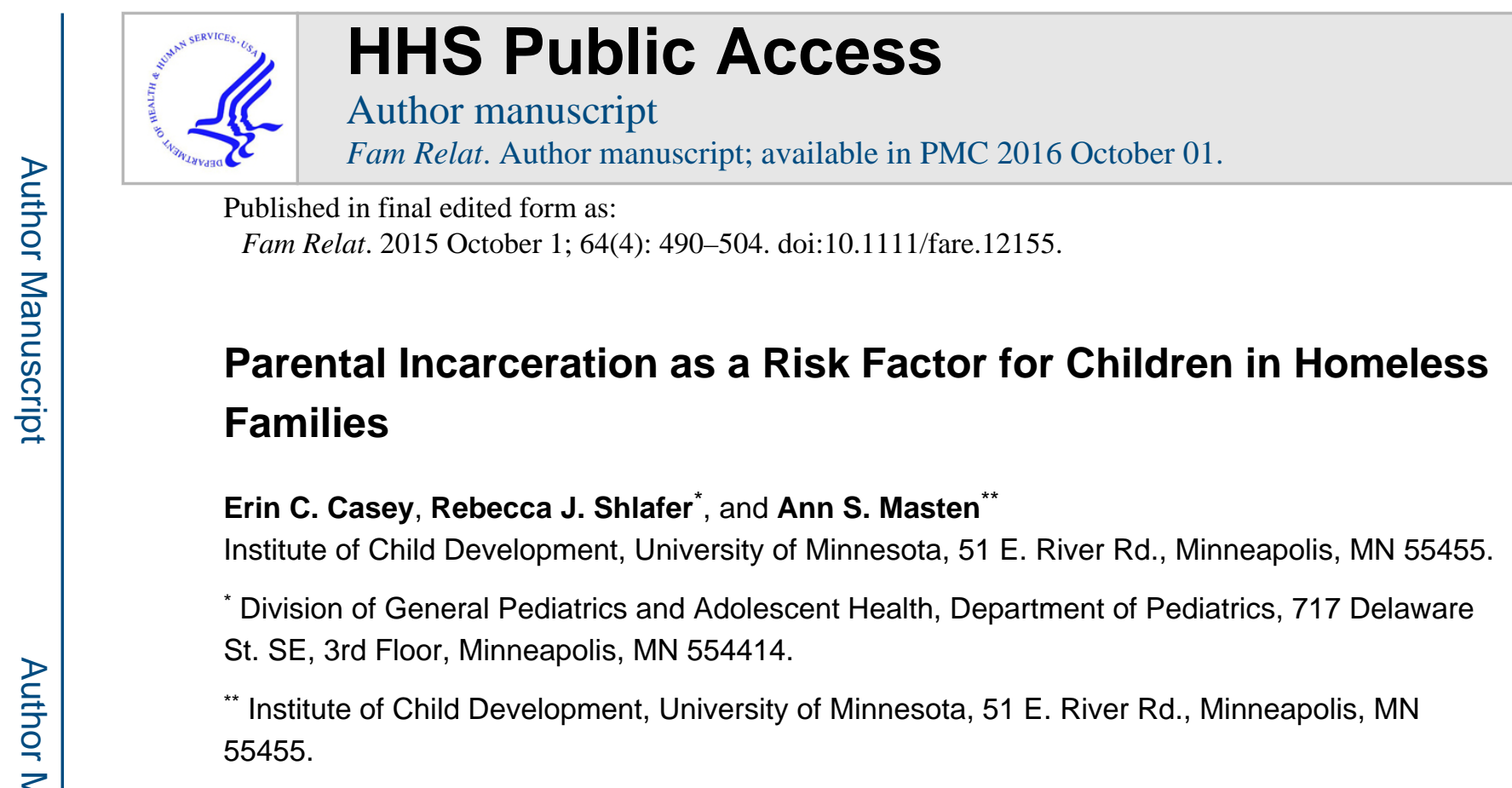

\begin{abstract}
The current study aimed to describe the prevalence of children of incarcerated parents (COIP) in a sample of homeless/highly mobile children, examine the relationship between parental incarceration and other risk factors, and investigate the effect of parental incarceration on child academic and mental health outcomes. The authors compared COIP $(n=45)$ to children whose parents were never incarcerated $(n=93)$ within a sample of 138,4 - to 7-year-old ethnically diverse children residing in emergency homeless shelters. Children's caregivers provided information about children's history of parental incarceration and other family experiences. Children's teachers reported academic and mental health outcomes in the subsequent school year. Compared to children with no history of parental incarceration, COIP experienced more negative life events. Regression models revealed that a history of parental incarceration was a significant predictor of teacher-reported internalizing problems. These results have implications for the identification and treatment of the highest risk homeless/highly mobile children.
\end{abstract}

Parental incarceration and family homelessness represent major risk factors for child development (e.g., Felitti et al., 1998). Moreover, each of these experiences has dramatically increased in the United States over the past two decades. Between 1980 and 2000, the number of adults incarcerated in state and federal prisons in the United States has more than tripled (Beck \& Gilliard, 1995; West \& Sabol, 2008). This rising rate of incarceration has left nearly 2 million children with at least one parent in prison (Glaze \& Maruschak, 2008). Millions more children have parents serving time in local jails (Kemper \& Rivara, 1993; Western \& Wildeman, 2009) or involved in community corrections through probation or parole. Over the same period, the rate of homelessness has also increased. Between 2007 and 2010, the number of homeless families and children across the United States rose $20 \%$ (U.S. Department of Housing and Urban Development, Office of Community Planning and Development, 2011). 
Homelessness and parental incarceration are both associated with an elevated risk for adverse outcomes in children and a history of cumulative family risk. Children of incarcerated parents (COIP) are at increased risk for internalizing and externalizing symptoms (Johnson, 2009; Kinner, Alati, Najman, \& Williams, 2007; Murray, Blijleveld, Farrington, \& Loeber, 2014; Pakiz, Reinherz, \& Gianconia, 1997), difficulties in school (Dallaire, Ciccone, \& Wilson, 2010; Hanlon et al., 2005; Murray \& Farrington, 2008), delinquency (Roettger, 2008), and criminal offending in adulthood (Huebner \& Gustafson, 2007; Murray \& Farrington, 2008; Murray, Janson, \& Farrington, 2007). Homeless/highly mobile (HHM) children are at risk for similar negative outcomes, including internalizing (Murray, Farrington, \& Sekol, 2012) and externalizing problems (Buckner, Bassuk, Weinreb, \& Brooks, 1999) and poor academic performance (Cutuli et al., 2013; Masten et al., 2014).

\section{The Intersection of Incarceration and Omelessness}

COIP and HHM children share many family-based risk factors associated with child problems, including poverty, racial/ethnic minority status, and a history of family violence and mental health problems. Yet, despite these patterns of co-occurring risks and problems, these two life events rarely have been considered in the same study, in particular in the context of families. The purpose of this study was to examine the prevalence of COIP status and related child outcomes in the context of family homelessness

Models of adversity in both developmental and family systems theory suggest that children in families who are coping with both homelessness and incarceration would have elevated risks for child problems. Family systems theory and family stress models predict that challenges within a family system (i.e., a parents' incarceration and family homelessness) could compromise the functioning of children within that family system (Conger et al., 2002; Masten \& Monn, 2015). The co-occurrence of these two risk factors is likely associated with high cumulative adversity in the child's life. Both theoretically and empirically, high cumulative risk has been linked to family dysfunction and child problems, including academic, social, and behavioral problems. (Evans, Li, \& Whipple, 2013; Obradovíc, Shaffer, \& Masten, 2012).

Research on adults has indicated a substantial overlap between a history of incarceration and current homelessness (Geller \& Curtis, 2011; Kushel, Hahn, Evans, Bangsberg, \& Moss, 2005; Metraux \& Culhane, 2006; Snow, Baker, \& Anderson, 1989; Tsai \& Rosenheck, 2012). In a survey of single individuals living in shelters in New York City, 23\% of the shelter population reported a history of incarceration in the previous 2 years (Metraux \& Culhane, 2006). An even larger percentage-approximately 33\% —of urban, homeless men surveyed by Geller and Curtis (2011) reported a history of incarceration. Estimates of incarceration history in single, homeless adults have been as high as $71 \%$ in other studies (Tsai \& Rosenbeck, 2012). Likewise, incarcerated adults report high rates of homelessness prior to their incarceration. In the year before their arrest, approximately $6 \%$ of state inmates experienced a period of homelessness; state inmates who reported a mental health problem were more than twice (13\%) as likely than inmates without a mental health problem to report being homeless (James \& Glaze, 2006). Furthermore, approximately 9\% of the 
parents incarcerated in state prisons reported a history of homelessness in the year before their arrest (Glaze \& Maruschak, 2008). Incarcerated mothers were twice as likely to report a period of homelessness than fathers (Glaze \& Maruschak, 2008).

Previous research also suggests that homelessness and incarceration often interact to create a pervasive cycle. Incarceration puts an individual at increased risk for homelessness (e.g., Kushel et al., 2005; Petersilia, 2001). With few financial resources, poor job training, housing restrictions for convicted felons, and the stigma associated with incarceration, many individuals rapidly become homeless following their release (Kushel et al., 2005). Indeed, previous estimates indicate that rates of homelessness range from $23 \%$ (Kushel et al., 2005) to as high as $50 \%$ (Petersilia, 2001) among parolees in urban areas. In turn, homelessness puts an individual at increased risk for subsequent incarceration. Homeless individuals are both more visible to law enforcement professionals than their housed peers and more likely to be arrested for petty crimes such as theft, public intoxication, and violation of a city ordinance (Greenberg \& Rosenheck, 2008; Snow et al., 1989).

Although the literature to date has focused almost exclusively on single adults' incarceration and homelessness, there is good reason to believe that these issues also intersect in the context of the family. Data collected in 2008 indicate that sizable portions of incarcerated men (53\%) were fathers (Maruschak, Glaze, \& Mumola, 2010), and although incarcerated men still outnumber incarcerated women, incarceration among women has risen substantially faster than among men, doubling between 1991 and 2007 (Maruschak et al., 2010). Among the 107,540 women incarcerated in the United States in $2007,61 \%$ were mothers of minor children, affecting an estimated 153,000 children (Maruschak et al., 2010). It is likely that these statistics substantially underestimate the true number of affected children given that there is no consistent collection of information about parenthood by law enforcement or states Departments of Corrections (Murray \& Farrington, 2008).

Furthermore, the data that are available come from self-reports of parenthood by inmates, a status that inmates may be unwilling to reveal to corrections staff upon entering the system for fear of repercussions involving custody and Child Protective Services.

Indeed, qualitative data demonstrate that parenthood and homelessness are not far from the minds of incarcerated parents. In an examination of the hopes and fears of incarcerated fathers, Meek (2011) reported that 30\% of men listed being a good father as one of their hopes after they leave prison. Many of the same men also listed homelessness as one of their fears following their release. Incarcerated men often leave behind families, many of whom may have counted on the financial support provided by the father prior to his arrest. The Bureau of Justice Statistics (Glaze \& Maruschak, 2008) reported that $54 \%$ of incarcerated fathers in state prison provided primary financial support of their minor children prior to their incarceration. Furthermore, nearly half $(46 \%)$ of parents in prison reported incomes below $\$ 1,000$ in the month before their arrest (Mumola, 2000). The high rate of incarceration among low-income parents may compromise a family's economic stability, leading to high levels of poverty and subsequent homelessness (Desmond, 2012). In one example of this cycle, Opsal (2011) found that, among female parolees, $49 \%$ were currently homeless. During their interviews many of the women discussed how they regretted the actions leading to their incarceration because those actions often left their children homeless. 
Thus, incarceration and homelessness are two common stressful life events among disadvantaged families that often appear to co-occur. The co-occurrence of COIP and homelessness in families could pose high cumulative risk to children in the family, given the direct and indirect risks associated with either of these experiences as well as their associations with other well-established risks for child development. Children experiencing homelessness are already facing disruptions in their home environments and, potentially, challenges with social and emotional development and academic adjustment. Homeless children who are also experiencing the incarceration of the parent have added instability in their caregiving environment and associated attachment relationships.

On the basis of the theoretical and empirical evidence on cumulative risk effects in families and children discussed above, we expected that HHM children whose parents have a history of incarceration would report more negative life experiences than HHM children whose parents do not have a history of incarceration. Thus, the overall objective of the present study was to examine risks associated with parental incarceration in a sample of families residing in an emergency shelter. This objective was achieved by pursuing the following three specific aims:

1. Examine the prevalence of COIP among HHM children and describe the situation in terms of family and child history. We expected a high rate of incarcerated parents among HHM families.

2. Compare the level and nature of negative life events reported for HHM children with and without a history of parental incarceration. We expected higher levels of negative life events for the COIP group compared to HHM without a history of parental incarceration.

3. Compare the mental health and achievement of HHM children with and without a history of parental incarceration. We expected that COIP would have an elevated risk for child mental health and academic problems compared to HHM children without a history of parental incarceration.

\section{Method}

\section{Participants}

In this study we drew on data from a larger project (e.g., Masten et al., 2012) that examined risk and resilience of children in HHM families transitioning to formal schooling (i.e., kindergarten and first grade). Participants were 138 pairs of adult primary caregivers and their 4- to 7-year-old children living in shelters serving homeless families in a large urban area in the midwestern region of the United States The majority of primary caregivers were biological mothers $(n=128,92.7 \%)$. The remaining caregivers were biological fathers $(n=$ $5,2.6 \%)$, stepmothers $(n=2,1.4 \%)$, stepfathers $(n=2,1.4 \%)$, and grandmothers $(n=1$, $0.7 \%$ ). Caregivers were, on average, 30 years, 9 months old ( $S D=6$ years, 4 months, range: 20 years, 6 months -57 years, 4 months). The mean age of children was 5 years, 9 months ( $S D=7$ months, range: 4 years, 10 months -6 years, 11 months). Of the 138 children interviewed, $78(56.5 \%)$ were female and $60(43.5 \%)$ were male. Self-reported race/ ethnicities were as follows: Two thirds of children $(n=88,63.8 \%)$ identified as African 
American, $16.7 \%(n=23)$ as multiracial, $5.8 \%(n=8)$ as American Indian, $4.3 \%(n=6)$ as Caucasian, $1.4 \%(n=2)$ as Asian or Pacific Islander, and $7.9 \%(n=11)$ as other.

\section{Procedure}

Data for this project were collected in two waves during the summers of 2008 and 2009. Participating families were recruited from three emergency shelters in a large metropolitan area in the Midwest. Recruitment strategies included fliers, letters, posters, recruitment booths in the shelters, and word of mouth among the parents. Families were eligible to participate if they spoke English and if their children expected to enter kindergarten or first grade the following fall and did not have a previously diagnosed developmental delay. Families interested in participating were invited to meet with the research staff on site to begin the consent process. The family and researcher entered a private room, where the researcher read the consent form aloud to caregivers to avoid assumptions of literacy. The researcher then answered any questions caregivers or children had about participation. The caregivers were compensated for their time with gift cards, and children received stickers and a small toy. After giving informed consent, caregivers and children were individually assessed in separate rooms with trained research assistants followed by a joint parent-child interaction session (not the focus of the current study). The total assessment lasted about 2 hours. With parent permission, the children's teachers were contacted at the beginning of the school year to complete the MacArthur Health and Behavior Questionnaire, Teacher Version (HBQ-T; Armstrong \& Goldstein, 2003; Lemery-Chalfant et al., 2007). Teachers received a gift card for returning the questionnaire.

\section{Measures}

A variety of instruments were used to assess participants' demographic characteristics, stress related to parenting, lifetime experience of negative and stressful events, and child functioning. All measures had been used successfully with similar populations in the past (e.g., Cutuli, Wiik, Herbers, Gunnar, \& Masten, 2010; Herbers et al., 2011). Furthermore, all surveys were read aloud to participants to avoid assumptions of literacy in this highly disadvantaged population. The surveys of interest to the current study are described below.

Family information questionnaire-This was a questionnaire completed by parents to gather information on sociodemographic characteristics, including caregiver and child age and ethnicity, caregiver education, family income, and family mobility information. Child ethnicity was coded to represent whether the child was identified as a racial/ethnic minority (1) or not (0).

Life Events Questionnaire-A short form of the LEQ (Masten et al., 1988) was administered to parents, including the 30 items comprising those included in the standard total score (independent of child behavior, negative or ambiguous but not positive, chronic and acute; see Masten, Milliotis, Graham-Berman, Ramirez, \& Neeman, 1993). Parents reported whether a list of 30 items had occurred in the past year (yes or no) of the child's life, including negative items (e.g., "During this past year, one of the child's parents died") and ambiguous events (e.g., "My child has a new brother or sister who as born during this 
past year"). We computed a total score (possible range: 0-30) and a negative subscale score (possible range: 0-24, which excludes the ambiguous set of items (see Table 1).

Life Time Events-The Life Time Events measure (Masten et al., 1993, 1999), completed by parents, provides a count of major negative life events (e.g., "Lived with a parent who had a serious alcohol or drug problem," "Been in a house fire") that have occurred at any point in a child's life. We used an adapted and expanded version developed for our research that includes the age of the child when an endorsed event occurred and whether or not the event had happened within the past month.

Parental incarceration-One of the items on the LTE addresses a child's history of parental incarceration (i.e., "Had a parent who was in prison"). Responses were dichotomized $(0=$ never had a parent in prison, $1=$ had a parent in prison). Caregivers who endorsed this item were asked a series of follow-up questions about which parent was incarcerated, the child's age at the time of the parent's most recent incarceration, the child's reaction to the separation from the incarcerated parent, the parent's current incarceration status, and the frequency and type of contact the child has with parent if the parent was incarcerated at the time of the interview.

Both measures of life events, the LEQ and the LTE, included an item assessing parental incarceration. In order to make an unbiased comparison of scores, we subtracted 1 point from the total scores on both measures for those children whose parent(s) had been incarcerated. We then compared the adjusted total LEQ and LTE scores of children who had experienced parental incarceration to the total LEQ and LTE scores of children whose parents had never been incarcerated (see Tables 2 and 3).

HBQ-T-With the caregivers' permission, children's teachers were contacted and asked to complete the HBQ-T. The original HBQ was developed to address the need for early detection of mental health symptoms in children younger than 9 years (Lemery-Chalfant et al., 2007). The measure assesses a wide range of child outcomes and consistently displays good measurement properties (e.g., Armstrong \& Goldstein, 2003; Obradovíc, 2010). Of interest to this study were children's internalizing and externalizing symptoms and academic functioning. Internalizing ( $\alpha=.92$ for the study sample) and externalizing symptoms ( $a=$. 91 for the study sample) were measured using a 3-point scale ranging from never/not true (0) to often or very true (2). The HBQ-T Academic Functioning composite score combines two scales. School Engagement (eight items; e.g., "approaches new activities with enthusiasm") was rated on a 3-point scale ranging from doesn't apply (0) to certainly applies (2), whereas Academic Competence (five items) was rated on a 5-point scale ( $1=$ not well at all, poor student to $5=$ very well, excellent student) for performance in five academic content areas (e.g., "How would you evaluate this child's current school performance in reading-related skills?"; $a=.96$ for the academic composite scale in the present sample). Total scores were calculated by summing endorsed items and averaging within each subscale (see Table 1). 


\section{Missing Data}

Despite high residential mobility of the sample, $83 \%$ of the children were located for followup. Furthermore, $97 \%$ of the teachers who were contacted returned questionnaires to yield HBQ-T reports for $83 \%$ of the original sample. Children without teacher data did not differ from those who had teacher reports on maternal education, history of parental incarceration, and number of life events experienced (i.e., total LEQ tally of negative and ambiguous events), $t(132)=-0.07, n s ; t(136)=-0.07, n s ;$ and $t(136)=-0.46, n s$, respectively. Children without follow-up data were excluded from the multiple regression analyses.

\section{Data Analysis}

The prevalence of COIP among this sample of HHM children is reported first, as are the descriptive characteristics of those children. We then report the frequency that each item on the LEQ and LTE were endorsed for each group and for the sample as a whole. We conducted independent-samples $t$ tests to compare total LEQ and LTE scores for children with and without a history of parental incarceration to test the hypothesis that parental incarceration would be associated with a history of more negative life experiences. Next, we used chi-square tests to compare the frequency of endorsement for each individual LEQ and LTE item to examine whether there was a significant difference in children's experience of specific life events depending on whether they had also experienced the incarceration of a parent.

Next, we examined descriptive statistics and bivariate correlations among key study variables. Variables that were significantly correlated with the outcome variables of interest were included as covariates in subsequent analyses. Finally, using multiple regression analyses, we tested whether parental incarceration was a significant predictor of children's internalizing, externalizing, and academic problems. The models included the following control variables: child sex, child lifetime residential mobility, and caregiver age, which were selected because each correlated significantly with at least one outcome of interest (see Table 1). The independent variable included in our models was the dichotomous COIP variable.

\section{Results}

\section{Descriptive Characteristics}

Descriptive statistics and bivariate correlations among key study variables are presented in Table 1. Of the 138 children, $32.6 \%(n=45)$ had a parent with a history of incarceration. Of those 45 children, $91 \%(n=41)$ had experienced their father's incarceration, $6.7 \%(n=3)$ had experienced the mother's incarceration, and 2.2\% $(n=1)$ had experienced the stepfather's incarceration. To test for potential differences between COIP who had experienced the incarceration of their biological father and COIP who had experienced the incarceration of another caregiver (i.e., their biological mothers or stepfather, $n=4$ ), we reran all analyses without the latter subset of children. The results were identical, and thus all COIP were retained in subsequent analyses, regardless of the child's relationship to the incarcerated parent. At the time of the parent's most recent arrest, children ranged from newborn to age 6 years ( $M=3$ years 1.5 months, $S D=1$ year, 8.94 months). Of the 45 
COIP, nearly half $(47.7 \%, n=21)$ were living with the parent at the time of the parent's arrest.

One in three $(33.3 \%, n=15)$ of the 45 participants who reported a history of parental incarceration indicated that the parent was currently incarcerated. Within those 15 cases we examined the type of contact the children had with their incarcerated parent. Nearly half $(46.7 \%, n=7)$ of the primary caregivers reported that the child had no contact with the incarcerated parent. Five (33.3\%) reported that the child's contact with the incarcerated parent was primarily by phone, two $(13.3 \%)$ reported that the contact was primarily through written letters, and one (6.7\%) reported that the child was able to visit the incarcerated parent on a regular basis.

\section{Life Events}

The results of independent-samples $t$ tests comparing the two groups of children indicated that there were no significant differences in total LTE scores between children whose parents had a history of incarceration $(M=2.36, S D=2.42)$ and children whose parents did not experience incarceration $(M=2.92, S D=2.23), t(136)=1.37, n s, d=-0.24$.

Furthermore, there were no significant differences between groups in the total LEQ score ( $M$ $=6.22, S D=2.40$ and $M=5.56, S D=2.93$, respectively), $t(136)=-1.32, n s, d=0.25$.

However, results for the Negative Life Events subscale score on the LEQ indicated a trend for scores to be higher among the children with a history of parental incarceration: ( $M=$ 4.51, $S D 1.93$ and $M=3.80, S D=2.39$, respectively), $t(136)=-1.75, p=.08, d=0.33$.

We next compared the likelihood of endorsement for each LEQ and each LTE item between groups. To account for the large number of tests, we corrected for multiple comparisons by computing a familywise error rate. We divided the $p<.05$ criterion by the number of times the test was conducted (i.e., 52) to yield a familywise error rate of $p<.001$. Chi-square analyses revealed significant group differences in the likelihood of experiencing the following events on the LEQ: an eviction from a house or apartment $\chi^{2}=(1, N=138)=$ $10.59, p<.001$, and a parent being arrested or going to jail in the past year $\chi^{2}=(1, N=138)$ $=27.78, p<.001$. For both events COIP were more likely to experience that event than their HHM peers who had not experienced parental incarceration (57.8\% vs. $29 \%$ [eviction] and $42.2 \%$ vs. $8.6 \%$ [arrest or jail]). After correcting for multiple comparisons, chi-square analyses revealed no significant group differences in the likelihood of experiencing any of the events listed on the LTE. The frequency of endorsement of each item on the LEQ and LTE and the results of chi-square analyses testing frequency of endorsement of specific items between groups are reported in Tables 2 and 3.

\section{Multiple Linear Regression Analyses}

Separate models were tested for each of the three outcomes, namely, internalizing behaviors (Model A), externalizing behaviors (Model B), and academic functioning (Model C). Each model included the following three covariates: (a) child control variables (sex and lifetime residential mobility), (b) caregiver control variable (age), and (c) the independent variable (dichotomous COIP variable). 
The results of the regression analyses are shown in Table 4. Both the overall models for internalizing and externalizing behaviors were significant, $F(4,106)=3.57, p=.01$, and $F(4,106)=2.64, p=.04$, respectively. However, whether a child had experienced parental incarceration accounted for unique variance in children's internalizing symptoms, but not in their externalizing symptoms or academic functioning. The COIP variable was related to internalizing symptoms even after accounting for child sex, lifetime residential mobility, and caregiver's age. This model predicted $12 \%$ of the total variance in internalizing symptoms.

In addition to the dichotomous COIP variable, child lifetime residential mobility, a covariate, also significantly predicted internalizing symptoms. Child sex was the only significant predictor of child externalizing behavior. Exploratory analyses to check for interaction effects of COIP with sex as a predictor showed no effects for any of the dependent variables.

\section{Discussion}

The first goal of the current study was to document the prevalence of COIP among HHM families, given that the intersection between these two populations has not been previously examined in the context of families. These data suggest a remarkably high co-occurrence, with nearly one third (32.6\%) of HHM children having experienced the incarceration of a parent. This finding is striking considering the average national rate of parental incarceration. Although just over $2 \%$ of the nation's children experience parental incarceration (Eddy \& Poehlmann, 2010), nearly one third of HHM children had a parent in jail or prison at some point in their lives. These data provide preliminary evidence of a disproportionately high prevalence of parental incarceration among children currently experiencing homelessness.

Although the HHM children in the present study experienced parental incarceration at rates far outpacing the national average, their experiences with parental incarceration are consistent with what other COIP experience. Children in the present study were more likely to experience a father's incarceration (91\%) than a mother's incarceration (6.7\%). This statistic is nearly identical to the national averages for COIP (West \& Sabol, 2008). In addition, these averages are consistent with the fact that the number of incarcerated men far surpasses that of women (e.g., Maruschak et al., 2010).

Data regarding children's contact with their incarcerated parents were also similar to previously reported data (Arditti, Lambert-Shute, \& Joest, 2003; Loper, Carlson, Levitt, \& Scheffel, 2009). Of the 15 children whose parents were incarcerated at the time of their participation, close to half did not have any contact with their incarcerated parents. Phone calls and letter writing were the most common forms of communication between the incarcerated parents and children who were in contact; only one child had regular in-person visits with the incarcerated parent.

We found a marginally significant difference between HHM children whose parents had experienced incarceration and other HHM children in the number of negative life events reported on the LEQ. On average, children whose parents had a history of incarceration 
experienced more negative life events than their HHM peers without incarcerated parents. Contrary to our hypothesis, no group differences were found in the combined total of negative and ambiguous events reported on the LEQ or in the number of negative life experiences reported on the LTE.

There are several reasons that might account for the lack of a difference in the total number of stressful life events found in this study. First, homelessness is generally an indicator of high cumulative risk, and thus the variance between groups, both of which were HHM, may be attenuated. Evidence for the high-risk nature of our sample is demonstrated by the percentage of children whose teachers' ratings of their internalizing and externalizing behaviors exceeded clinical threshold for these scales. Nearly one quarter of all children $(n=$ $25,22.7 \%)$ exceeded the clinical threshold for externalizing behavior, and $16.4 \%(n=18)$ exceeded the threshold for internalizing behavior. These rates are notably higher than rates reported in previous work with typically developing samples of children in this same age range who have not experienced parental incarceration (e.g., $14.0 \%$ exceeding the threshold for externalizing behaviors, $12.2 \%$ exceeding the threshold for internalizing behaviors; Lemery-Chalfant et al., 2007). Second, there is no reason to expect that all stressful events would be more prevalent among families with an incarcerated parent. Ambiguous events, such as the birth of a new sibling, may be more evenly distributed between children with and without a history of incarcerated parents. In contrast, many of the objectively negative events would conceivably occur more often for children whose parents have a history of incarceration (e.g., having a parent with a drug or alcohol problem or exposure to violence). With more than half (58.1\%) of inmates in national samples reporting drug use in the month prior to their offense (Mumola, 2000), children may likely experience a parent's drug or alcohol problems prior to the parent's incarceration. Some parents' crimes may include violence toward their children or may expose their children to the violence in their home or communities. Therefore, it is not surprising that only the number of objectively negative events differed between groups in this sample.

Item-by-item comparisons supported the idea that it is only objectively negative life events that are more common among COIP (see Tables 2 and 3). Chi-square tests revealed significant differences in the proportion of children who experienced eviction from a house or apartment (57.8\% of COIP vs. $29 \%$ of their HHM peers) and parental arrest or incarceration in jail in the past year (42.2\% vs. $8.6 \%)$. Several other objectively negative life events were experienced more frequently by COIP, although the group differences in the likelihood of experiencing these events did not reach statistical significance after correcting for the familywise error rate. For instance, COIP more frequently experienced a difficult family financial situation, lived with a parent with a serious alcohol or drug problem, experienced fights between adults taking care of them, lived in foster care, and had seen violence happening to other people. There were much smaller group differences in the number of ambiguous events such the birth of a sibling, a new adult living with the family, or a parent remarrying, none of which were statistically significant.

The lack of a significant difference in LTE scores between the groups may also be explained by a closer examination of the random or nonrandom nature of the individual items (see Tables 2 and 3). Although the LTE measure does not allow for subscale scores that 
distinguish negative events from ambiguously stressful events in the way the LEQ does, individual items from both measures could be conceptually grouped into random versus nonrandom negative events. One would not necessarily expect children with incarcerated parents to experience random negative events (e.g., a natural disaster or being attacked by an animal) at a rate higher than their peers. The LTE contains more of these random negative events than the LEQ. Item-level comparisons (see Tables 2 and 3) support this idea, with larger group differences for nonrandom events; that is, COIP were not more likely to experience events that seem unrelated to a parent's history of involvement in the criminal justice system, such as a natural disaster or being attacked by an animal. COIP were, however, more likely to experience events that are often related to parental incarceration, such as a parent's involvement with drugs or alcohol or witnessing violence happening to other people. The LTE has more items that seem unrelated to parental incarceration than does the LEQ. Thus, the nonsignificant difference in LTE scores between groups may be due to the unpredictable nature of several items on the scale.

We found that a history of parental incarceration significantly predicted children's internalizing symptoms, accounting for $12 \%$ of the total variance in internalizing symptoms. This relationship was maintained even after child sex, residential mobility, and caregiver age were accounted for. These findings align with predictions made from a family systems perspective. Family systems theorists recognize that factors operating on the family system in which a child resides (e.g., economic stress contributing to parent's criminal actions, changes in sentencing laws) have direct implications for child functioning. Furthermore, our results are consistent with past research linking parental incarceration to adverse child mental health outcomes (e.g., Johnson, 2009; Kinner et al., 2007). However, a recent metaanalysis by Murray and colleagues (Murray et al., 2012) found that parental incarceration predicted externalizing problems, rather than internalizing problems, whereas in the current study we found the opposite pattern of results. None of the studies included in the metaanalysis, however, examined HHM children as the current study did. Our findings show that the relationship between parental incarceration and internalizing problems, but not externalizing problems, is maintained even when one is considering COIP in comparison to other extremely high-risk children (i.e., HHM children).

The existence of this direct association in HHM children is striking when one considers the extreme disadvantage these children experience. Research often has demonstrated that it is often not any one specific risk factor, but the cumulative effect of many co-occurring risk factors, that is predictive of adverse child outcomes (e.g., Evans et al., 2013; Obradović et al., 2012). One might expect the variety and number of risk factors that HHM children experience to overwhelm the unique predictive significance of any one specific risk factor; however, this was not the case with parental incarceration in this sample, suggesting that parental incarceration is a particularly salient life event for children's internalizing symptoms. This idea may also explain why, despite being a significant predictor, COIP accounted for a relatively small amount of the total variance in internalizing behavior. These group differences in internalizing symptoms, even given their small magnitude, are important given the implications for children's future behavior, social adjustment, and academic achievement (e.g., Boivin, Petitclerc, Feng, \& Barker, 2010). 
Although we did find that COIP experienced more internalizing symptoms, we did not find these children to be at unique risk for externalizing behavior problems or academic problems when compared to their HHM peers. One explanation for the lack of significant differences concerns the high-risk nature of our sample. The mean externalizing score of our sample was far above national norms, and the mean academic functioning was well below national norms, a pattern that is consistent with past research documenting the extreme disadvantage faced by HHM samples (e.g., Masten et al., 2014). Our group comparison, then, of HHM children who did and did not have a history of parental incarceration is a comparison of two very high-risk samples. Thus, group differences in outcomes may be particularly difficult to identify above and beyond the already very high rates of externalizing problems and low academic functioning.

Another potential explanation of the nonsignificant academic model concerns the young age of the children in our sample, who were just entering kindergarten or first grade. It is conceivable that group differences in academic performance would not manifest this early in a child's educational career, but one might still expect larger differences in the future as the academic rigor and expectations placed on students increase with children's age.

Another possibility for the lack of differences in externalizing problems and academic achievement between children with and without a history of parental incarceration concerns the timing of the parental incarceration. Data on the exact timing of the parents' incarcerations were not available. Thus, COIP in this sample could have been experiencing the current incarceration of a parent or could have experienced the incarceration of their parent in the past (e.g., for only a brief period of time while they were still in infancy). Perhaps externalizing problems and academic difficulties are acute reactions to more recent experiences of parental incarceration. Future studies should collect more detailed information on when in a child's life course the incarceration occurred, to better examine the effect of timing of parental incarceration.

This study focused on risk rather than resilience as a first step in examining the possible effects of co-occurring incarceration and homelessness on young children. However, despite the substantial risks faced by HHM children and COIP, there is good reason to expect that variations in promotive or protective factors, as well as cumulative risks, may play a role in the well-being of children in homeless families (e.g., Cutuli et al., 2013; Masten et al., 2012, 2014; Obradovíc et al., 2009). Future work should seek to identify protective factors that promote resilience in children experiencing the co-occurring risks of homelessness and parental incarceration. Theory and previous work suggest that factors such as effective parenting (Herbers, Cutuli, Monn, Narayan, \& Masten. 2014), children's executive functioning (Masten et al., 2012), supportive relationships with an unrelated adult (e.g., teacher; Werner \& Smith, 1992), spirituality, and positive peer relationships (Nesmith \& Ruhland, 2008) are associated with adaptive outcomes in children in similar contexts. Particular attention should be paid to malleable protective factors that may serve as targets of interventions designed for this unique population of children (Poehlmann \& Eddy, 2010).

The current study has several limitations that should be considered when interpreting the results. First, with a relatively small sample size of only 45 COIP, we did not have the 
statistical power to investigate subgroup differences. Furthermore, although interesting and relevant variables surrounding the incarceration experience were collected (e.g., whether the child was living with the parent at the time of his or her arrest and incarceration), data on other potentially relevant variables were not collected (e.g., length of parental incarceration, frequency of parental incarceration). Future research with a larger sample of HHM children who have experienced parental incarceration may be better suited to address additional sources of heterogeneity. Some factors that likely affect the association between parental incarceration and child outcomes include the age of the child at the time of the parent's incarceration (Johnston, 1995), the duration of incarceration, the child's previous relationship with the incarcerated parent (e.g., custodial vs. noncustodial parents), and the stability of the caregiving situation during parental incarceration.

Although many homeless families do seek emergency shelter services in the urban context of this study, they may also be living in different circumstances. For instance, a family may "double-up" and stay at a family member or friend's home. Alternatively, they may live in a car, a park, or on the street. Our sample included only families who were staying in shelters, and thus the generalizability of our results is limited to sheltered homeless families. It is worth noting, though, that most homeless families with young children often do reside in a shelter (Buckner et al., 1999). Furthermore, the shelters sampled for the present study do house the majority of families who use emergency shelter in this particular metro area (Cutuli et al., 2014).

Another limitation concerns the wording of the item that probed for a history of parental incarceration. The item asks whether the child "had a parent who was in prison." This wording, which was retained from the original measure, may have led to an underestimation of the number of children in the sample who experienced parental incarceration, given that it likely did not include parents who went to jail. Many individuals in the criminal justice system make a distinction between jail and prison, due in part to differences in sentence length and living circumstances at these different types of correctional facilities. Caregivers of children with a parent incarcerated in jail, but not in prison, may be unlikely to endorse the item because of the explicit use of the word prison. Partial empirical support of this idea is found when one considers that $8.6 \%$ of parents of children who did not endorse the LTE item "had a parent who was in prison" did endorse the LEQ item "A parent was arrested or went to jail in the past year." Although it is possible that these individuals were arrested only briefly, without being incarcerated, it is also possible that they experienced incarceration in a jail, but not a prison.

In addition, for participants who did report jail stays despite the wording of the item, we did not distinguish between incarcerations in jail versus prison. Jail stays are often shorter, and jail inmates are more likely than prison inmates to cycle in and out of the criminal justice system (Eddy \& Poehlmann, 2010). Thus, children whose parents have a history of incarceration in jails may have experienced more frequent and repetitive separations from their parent. These children presumably also have more experiences witnessing the arrest of their parent, a particularly traumatic event. Future research should examine differences in outcomes between children of parents incarcerated in a jail and children of parents incarcerated in a state or federal prison. Last, the current study considered only a restricted 
age range of children entering kindergarten or first grade. Thus, the findings can be generalized only to relatively young children and not to others who may experience parental incarceration in middle childhood or adolescence.

Despite these limitations, the current study represents a unique contribution to the literature on COIP, as well as the literature on HHM children. To our knowledge, this is the first study to examine children's outcomes and their concurrent experience of these two risk factors. Although all children living in emergency shelters are clearly at risk, there exists striking variability within the population. This study represents an effort to parse that heterogeneity by investigating one subgroup of HHM children: those whose parents have a history of incarceration. Our findings suggest that COIP currently experiencing homelessness have elevated risk for symptoms of internalizing problems, such as anxiety, fear, and depressed mood, although they do not exhibit greater risk for externalizing or academic problems when compared to other HHM children. Our results showing an increased risk for internalizing problems have implications for the identification and treatment of HHM children who are at an even higher risk for mental health problems than their peers. Our findings underscore the importance of social workers and other professionals working with children in shelters and within the criminal justice system to consider the possibility of cooccurring risks of homelessness and incarceration of a parent as early as possible in order to provide intervention services. Early intervention is particularly critical for children experiencing multiple risks so that family service professionals can take advantage of the potential for a positive cascade of effects in an individual's developmental trajectory (e.g., decreased internalizing problems in childhood, leading to increased academic engagement in middle childhood, leading to better career attainment in adulthood). Although the risk factors identified in the current study (i.e., homelessness and the incarceration of a parent) are associated with adverse outcomes, they also equip professionals with the knowledge to identify and support children at particularly high risk earlier in their developmental trajectory.

\section{Acknowledgments}

The research reported in this article was supported by Grant 0745643 from the National Science Foundation Ann S. Masten. Preparation of this article was also supported by a University of Minnesota Center for Cognitive Sciences Fellowship award to Erin C. Casey and by National Center for Advancing Translational Sciences of the National Institutes of Health Award UL1TR0000114. The opinions expressed are those of the authors and do not represent views of the National Science Foundation, the National Institutes of Health, the Center for Cognitive Sciences, or other funders. We thank all the families who participated in this study and the research staff who made this study possible.

\section{References}

Arditti JA, Lambert-Shute J, Joest K. Saturday morning at the jail: Implications of incarceration for families and children. Family Relations. 2003; 52:195-204. doi:10.111/j.1741-3729.2003.00195.x.

Armstrong, JM.; Goldstein, LH. Manual for the MacArthur Health \& Behavior Questionnaire (HBQ 1.0). University of Pittsburgh Press; Pittsburgh, PA: 2003.

Beck, AJ.; Gillard, DK. Prisoners in 1994. U.S. Department of Justice; Washington, DC: 1995. NCJ Report No. 151654

Boivin M, Petitclerc A, Feng B, Barker ED. The developmental trajectories of peer victimization in middle to late childhood and the changing nature of their behavioral correlates. Merrill-Palmer Quarterly. 2010; 56:231-260. doi:10.1353/mpq.0.0050. 
Buckner JC, Bassuk EL, Weinreb LF, Brooks MG. Homelessness and its relation to mental health and behavior of low-income school-age children. Developmental Psychology. 1999; 35:246-257. doi: 10.1037/0012-1649.35.1.246. [PubMed: 9923479]

Conger RD, Wallace LE, Sun Y, Simons RL, McLoyd VC, Brody GH. Economic pressure in African American families: A replication and extension of the family stress model. Developmental Psychology. 2002; 38:179-193. doi:0.1037//0012-1649.38.2.179. [PubMed: 11881755]

Cutuli JJ, Desjardins CD, Herbers JE, Long JD, Heistad D, Chan C, Masten AS. Academic achievement trajectories of homeless and highly mobile students: Resilience in the context of chronic and acute risk. Child Development. 2013; 84:841-857. doi:10.111/cdev.12013. [PubMed: 23110492]

Cutuli JJ, Herbers JE, Lafavor TL, Ahumada SM, Masten AS, Oberg C. Asthma and adaptive functioning among homeless kindergarten-aged children in emergency housing. Journal of Health Care for the Poor and Underserved. 2014; 25:717-730. doi:10.1353/hpu.2014.0099. [PubMed: 24858881]

Cutuli JJ, Wiik KL, Herbers JE, Gunnar MR, Masten AS. Cortisol function among early school-aged homeless children. Psychoneuroendocrinology. 2010; 35:833-845. doi:10.1016/j.psyneuen. 2009.11.008. [PubMed: 20022181]

Dallaire DH, Ciccone A, Wilson L. The relation of exposure to parental criminal activity, arrest, and sentencing to children's maladjustment. Journal of Child and Family Studies. 2010; 19:404-418. doi:10.1016/j.appdev.2010.04.001.

Desmond M. Eviction and the reproduction of urban poverty. American Journal of Sociology. 2012; 118:88-133.

Eddy, JM.; Poehlmann, J. Children of incarcerated parents: A handbook for researchers and practitioners. The Urban Institute; Washington, DC: 2010.

Evans GW, Li D, Whipple SS. Cumulative risk and child development. Psychological Bulletin. 2013; 139:1342-1396. doi:10.1037/a0031808. [PubMed: 23566018]

Felitti VJ, Anda RF, Nordenberg D, Williamson DF, Spitz AM, Edwards V, Marks JS. Relationship of childhood abuse and household dysfunction to many of the leading causes of death in adults. The Adverse Childhood Experiences (ACE) Study. American Journal of Preventive Medicine. 1998; 14:245-258. doi:10.1016/S0749-3797(98)00017-8. [PubMed: 9635069]

Geller A, Curtis MA. A sort of homecoming: Incarceration and the housing security of urban men. Social Science Research. 2011; 40:1196-1213. doi:10.1016/j.ssresearch.2011.03.008. [PubMed: 21927519]

Glaze, LE.; Maruschak, LM. Parents in prison and their minor children. Bureau of Justice Statistics Special Report, U.S. Department of Justice, Office of Justice Programs, Bureau of Justice Statistics; Washington, DC: 2008.

Greenberg GA, Rosenheck RA. Jail incarceration, homelessness, and mental health: A national study. Psychiatric Services. 2008; 59:170-177. [PubMed: 18245159]

Hanlon TE, Blatchley RJ, Bennett-Sears T, Grady KE, Rose M, Callaman JM. Vulnerability of children of incarcerated addicted mothers: Implications for preventative interventions. Children and Youth Services Review. 2005; 27:67-84. doi:10.106/j.childyouth.2004.07.004.

Herbers JE, Cutuli JJ, LaFavor TL, Vrieze D, Leibel C, Obradovíc J, Masten AS. Direct and indirect effects of parenting on the academic functioning of young homeless children. Early Education \& Development. 2011; 22:77-104. doi:10.1080/10409280903507261.

Herbers JE, Cutuli JJ, Monn AR, Narayan AJ, Masten AS. Trauma, adversity, and parent-child relationships among young children experiencing homelessness. Journal of Abnormal Child Psychology. 2014; 42:1162-1174. doi:10.1007/s10802-014-9868-7.

Huebner BM, Gustafson R. The effect of maternal incarceration on adult offspring involvement in the criminal justice system. Journal of Criminal Justice. 2007; 35:283-296. doi:10.1016/j.jcrimjus. 2007.03.005.

James, DJ.; Glaze, LE. Mental health problems of prison and jail inmates. U.S. Department of Justice, Office of Justice Programs, Bureau of Justice Statistics; Washington, DC: 2006. 
Johnson, R. Ever-increasing levels of parental incarceration \& the consequences for children.. In: Pattillo, M.; Weiman, D.; Western, B.; B., editors. Do prisons make us safer? The benefits and costs of the prison boom. Russell Sage Foundation; New York: 2009. p. 97-131.

Johnston, D. Effects of parental incarceration.. In: Gabel, K.; Johnston, D., editors. Children of incarcerated parents. Lexington Books; New York: 1995. p. 59-88.

Kemper KJ, Rivara FP. Parents in jail. Pediatrics. 1993; 92:261-264. [PubMed: 8337027]

Kinner SA, Alati R, Najman JM, Williams GJ. Do parental arrest and imprisonment lead to child behavior problems and substance use? A longitudinal analysis. Journal of Child Psychology and Psychiatry. 2007; 48:1148-1156. doi:10.1111/j.1469-7610.2007.01785.x. [PubMed: 17995491]

Kushel MB, Hahn JA, Evans JL, Bangsberg DR, Moss AR. Revolving doors: Imprisonment among the homeless and marginally housed population. American Journal of Public Health. 2005; 95:17471752. doi:10.2105/AJPH.2005.065094. [PubMed: 16186453]

Lemery-Chalfant K, Schreiber JE, Schmidt NL, Van Hulle CA, Essex MJ, Goldsmith HH. Assessing internalizing, externalizing, and attention problems in young children: Validation of the MacArthur HBQ. Journal of the American Academy of Child \& Adolescent Psychiatry. 2007; 46:1313-1323. doi:10.1097/chi.0b013e3180f616c6.

Loper AB, Carlson LW, Levitt L, Scheffel K. Parenting stress, alliance, child contact, and adjustment of imprisoned mothers and fathers. Journal of Offender Rehabilitation. 2009; 48:483-503. doi: 10.1080/10509670903081300.

Maruschak, LM.; Glaze, LE.; Mumola, CJ. Incarcerated parents and their children: Findings from the Bureau of Justice Statistics.. In: Eddy, M.; Poehlmann, J., editors. Children of incarcerated parents: A handbook for researchers and practitioners. The Urban Institute; Washington, DC: 2010. p. 33-51.

Masten AS, Cutuli JJ, Herber JE, Hinz E, Obradović J, Wenzel AJ. Academic risk and resilience in the context of homelessness. Child Development Perspectives. 2014; 8:201-206. doi:10.111/cdep. 12088.

Masten AS, Garmezy N, Tellegen A, Pellegrini DS, Larkin K, Larsen A. Competence and stress in school children: The moderating effects of individual and family qualities. Journal of Child Psychology and Psychiatry. 1988; 29:745-764. doi:10.1111/j.1469-7610.1988.tb00751.x. [PubMed: 3235488]

Masten AS, Herbers JE, Desjardins CD, Cutuli JJ, McCormick CM, Sapienza JK, Zelazo PD. Executive function skills and school success in young children experiencing homelessness. Educational Researcher. 2012; 41:375-384. doi:10.3102/0013189X12459883.

Masten AS, Monn AR. Child and family resilience: A call for integrated science, practice, and professional training. Family Relations. 2015; 64:5-21. doi:10.1111/fare.12103.

Meek R. The possible selves of young fathers in prison. Journal of Adolescence. 2011; 34:941-949. doi:10.1016/j.adolescence.2010.12.005. [PubMed: 21334059]

Metraux S, Culhane DP. Recent incarceration history among a sheltered homeless population. Crime \& Delinquency. 2006; 52:504-517. doi:10.1177/0011128705283565.

Mumola, CJ. Incarcerated parents and their children. U.S. Department of Justice, Office of Justice Programs; Washington, DC: 2000. Report No. NCJ 182335

Murray, J.; Blijleveld, CCJH.; Farrington, DP.; Loeber, R. Effects of parental incarceration on children: Cross-national comparative studies. American Psychological Association; Washington, DC: 2014.

Murray J, Farrington DP. The effects of parental imprisonment on children. Crime and Justice. 2008; 37:133-206. doi:10.1086/520070.

Murray J, Farrington DP, Sekol I. Children's antisocial behavior, mental health, drug use, and educational performance after parental incarceration. Psychological Bulletin. 2012; 138:175-210. doi:10.1037/a0026407. [PubMed: 22229730]

Murray J, Janson CG, Farrington DP. Crime in adult offspring of prisoners: A cross-national comparison of two longitudinal samples. Criminal Justice and Behavior. 2007; 34:133-149. doi: $10.1177 / 0093854806289549$. 
Nesmith A, Ruhland E. Children of incarcerated parents: Challenges and resiliency, in their own words. Children and Youth Services Review. 2008; 30:1119-1130. doi:10.1016/j.childyouth. 2008.02.006.

Obradović J. Effortful control and adaptive functioning of homeless children: Variable-focused and person-focused analyses. Journal of Applied Developmental Psychology. 2010; 31:109-117. doi: 10.1016/j.appdev.2009.09.004. [PubMed: 20401161]

Obradovíc J, Long JD, Cutuli JJ, Chan C, Hinz E, Heistad D, Masten AS. Academic achievement of HHM children in an urban school district: Longitudinal evidence on risk, growth, and resilience. Development and Psychopathology. 2009; 21:493-518. doi:10.1017/S0954579409000273. [PubMed: 19338695]

Obradović, J.; Shaffer, A.; Masten, AS. Risk and adversity in developmental psychopathology: Progress and future directions.. In: Mayes, LC.; Lewis, M., editors. The Cambridge handbook of environment in human development environment of human development: A handbook of theory and measurement. Cambridge University Press; New York: 2012. p. 35-37.

Opsal TD. Women disrupting a marginalized identity: Subverting the parolee identity through narrative. Journal of Contemporary Ethnography. 2011; 40:135-167. doi: 10.117/0891241610384995.

Pakiz B, Reinherz HZ, Giaconia RM. Early risk factors for serious antisocial behavior at age 21: A longitudinal community study. American Journal of Orthopsychiatry. 1997; 67:91-101. doi: 10.1037/h0080214.

Petersilia J. Prisoner reentry: Public safety and reintegration challenges. The Prison Journal. 2001; 81:360-375. doi:10.1177/0032885501081003004.

Poehlmann, J.; Eddy, JM. Research and intervention agenda for COIP.. In: Eddy, JM.; Poehlmann, J., editors. Children of incarcerated parents: A handbook for researchers and practitioners. The Urban Institute Press; Washington, DC: 2010. p. 319-341.

Roettger, ME. Three essays on social inequality and the U.S. criminal justice system. University of North Carolina at Chapel Hill; 2008. (Unpublished doctoral dissertation) doi:10.1093/aje/kwr409

Snow DA, Baker SG, Anderson L. Criminality and homeless men: An empirical assessment. Social Problems. 1989; 36:532-549. doi:10.2307/3096817.

Tsai J, Rosenheck RA. Incarceration among chronically homeless adults: Clinical correlates and outcomes. Journal of Forensic Psychology Practice. 2012; 12:307-324. doi: 1080/15228932.2012.695653.

U.S. Department of Housing and Urban Development, Office of Community Planning and Development. The 2010 annual homeless assessment report to Congress. Author; Washington, DC: 2011.

Werner, EE.; Smith, RS. Overcoming the odds: High-risk children from birth to adulthood. Cornell University Press; Ithaca, NY: 1992.

West, HC.; Sabol, WJ. Prisoners in 2007. U.S. Department of Justice, Bureau of Justice Statistics; Washington, DC: 2008. Report No. NCJ 224280

Western B, Wildeman C. The Black family and mass incarceration. Annals of the American Academy of Political and Social Science. 2009; 621:221-242. doi:10.1177/00027162083248502.

Fam Relat. Author manuscript; available in PMC 2016 October 01. 

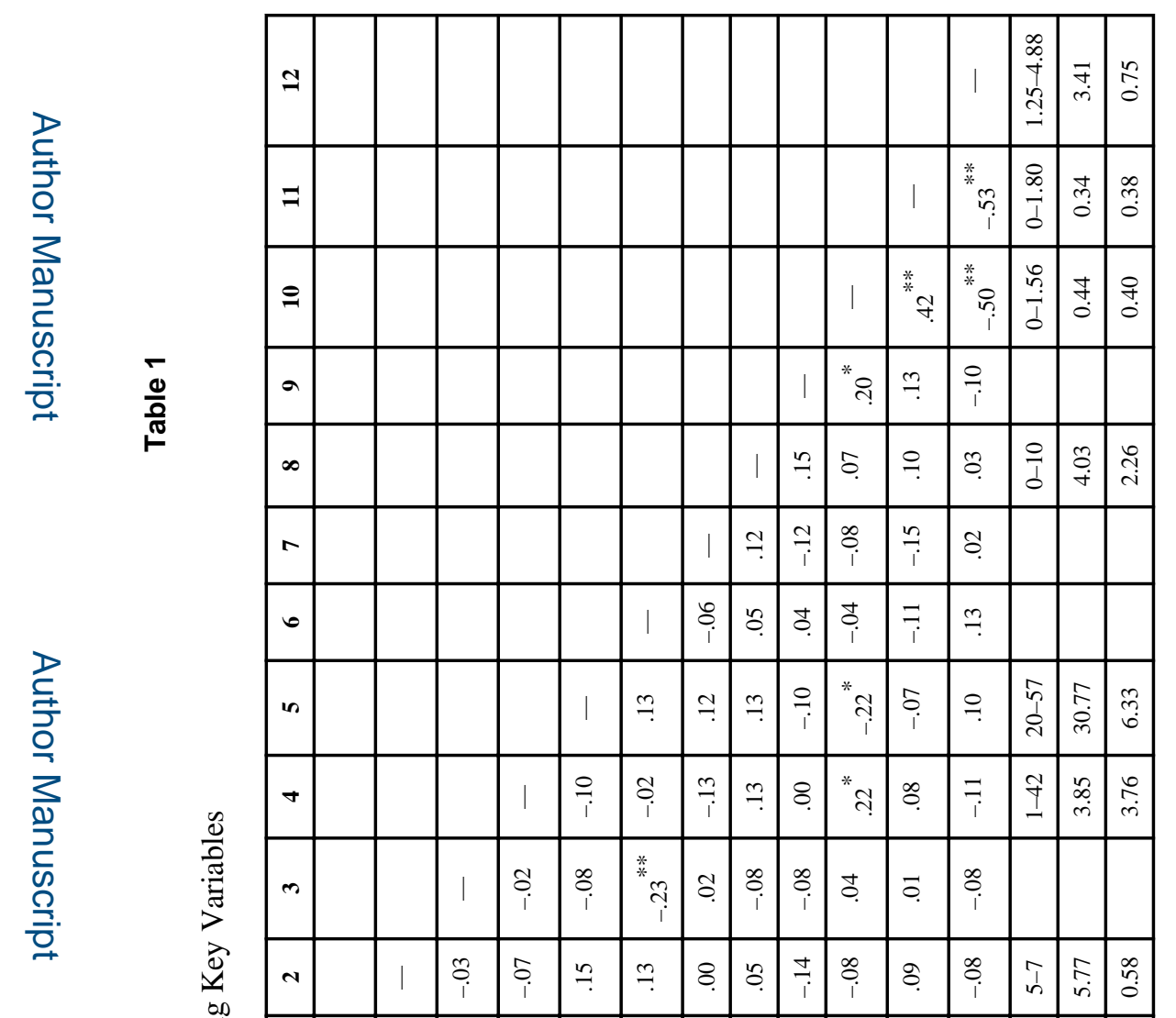

로을

\begin{tabular}{|c|c|c|c|c|c|c|c|c|c|c|c|c|c|c|c|}
\hline-1 & I & $\overline{0}$ & $\stackrel{\rho}{i}_{i}$ & 5 & $\stackrel{\varepsilon}{\circ}$ & $\bar{\sigma}$ & $\exists$ & $\underset{1}{7}$ & $\mid \begin{array}{c}0 \\
0 \\
1\end{array}$ & $\bar{\sigma}_{i}$ & ${ }^{*}$ " & $\bar{i}_{i}$ & & & \\
\hline 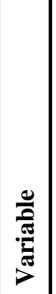 & 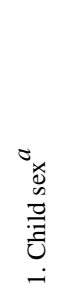 & 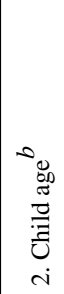 & 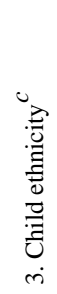 & 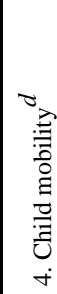 & 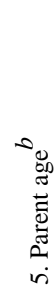 & 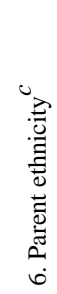 & 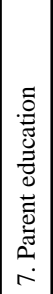 & 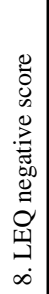 & 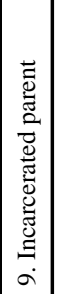 & 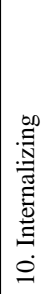 & 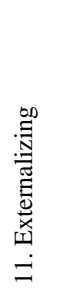 & 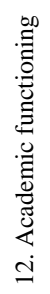 & & 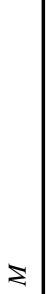 & คิ \\
\hline
\end{tabular}

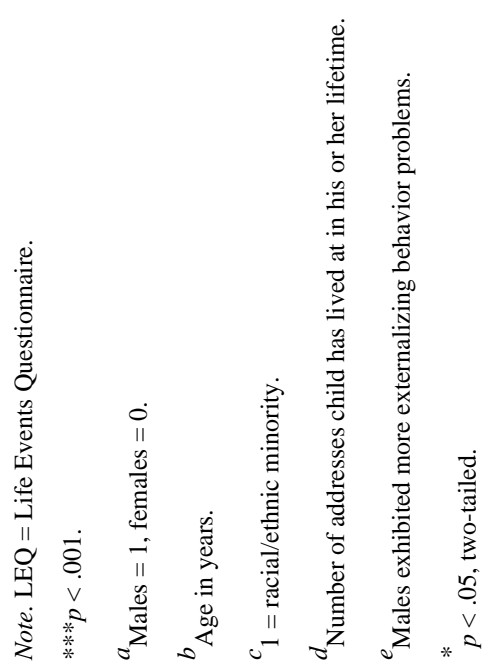

Fam Relat. Author manuscript; available in PMC 2016 October 01. 
】

\begin{tabular}{|c|c|c|c|c|c|c|c|c|c|c|c|c|c|c|c|c|c|c|c|c|c|c|c|c|c|c|}
\hline & $\overbrace{}^{2}$ & 吕 & ঙิ & 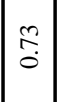 & $\stackrel{0}{0}$ & $\mid \begin{array}{c}\infty \\
\substack{0 \\
0}\end{array}$ & $\overrightarrow{0}$ & \begin{tabular}{|l|}
$\infty$ \\
$\stackrel{0}{0}$
\end{tabular} & & $\begin{array}{l}8 \\
0 \\
0\end{array}$ & $\stackrel{0}{-}$ & $\overline{0}$ & $\mid \begin{array}{l}n \\
n \\
i\end{array}$ & \begin{tabular}{|l|}
0 \\
0 \\
0
\end{tabular} & $\left|\begin{array}{l}\infty \\
\stackrel{i}{i}\end{array}\right|$ & $\hat{n}$ & $\stackrel{8}{0}$ & $\mid$\begin{tabular}{l|}
$\infty$ \\
0 \\
0
\end{tabular} & $\stackrel{m}{0}$ & nे & $\begin{array}{l}\infty \\
\stackrel{\infty}{r} \\
\end{array}$ & $\begin{array}{l}0 \\
0 \\
0\end{array}$ & $\begin{array}{l}{ }^{*} \\
\text { nิ } \\
\text { ô }\end{array}$ & 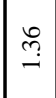 & $\begin{array}{l}\stackrel{一}{+} \\
\dot{+}\end{array}$ & gे \\
\hline 节 & $\begin{array}{l}\hat{o} \\
\hat{z} \\
\bar{\theta}\end{array}$ & $\vec{m}$ & 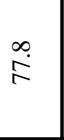 & \begin{tabular}{|l|} 
\\
+ \\
\end{tabular} & $\begin{array}{c}m \\
\tilde{g}\end{array}$ & $\tilde{A}$ & $\begin{array}{l}\therefore 0 \\
\stackrel{2}{2}\end{array}$ & 0 & 0 & 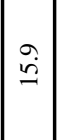 & $\stackrel{+}{+}$ & 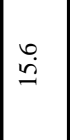 & הี & $\begin{array}{l}0 \\
\dot{i}\end{array}$ & $\tilde{\lambda}$ & $\stackrel{+}{+}$ & 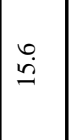 & $\vec{m}$ & $\mid \begin{array}{c}\stackrel{\partial}{o} \\
\dot{\alpha}\end{array}$ & $\underset{\dot{d}}{\stackrel{\alpha}{d}}$ & $\begin{array}{c}m \\
\tilde{\alpha}\end{array}$ & \begin{tabular}{|c|c|}
$\dot{0}$ \\
$\tilde{m}$
\end{tabular} & $\begin{array}{l}\text { : } \\
\text { in }\end{array}$ & \begin{tabular}{|l|l}
$\infty$ \\
$\dot{m}$ \\
$\dot{\infty}$
\end{tabular} & $\overrightarrow{\dot{m}}$ & 0 \\
\hline 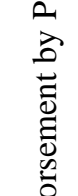 & 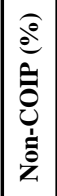 & 命 & $\begin{array}{l}\infty \\
\dot{0} \\
\dot{g}\end{array}$ & $\begin{array}{l}0 \\
\infty \\
\infty\end{array}$ & $\mid \begin{array}{l}\dot{\mathcal{I}} \\
\end{array}$ & $\exists$ & $\mid \begin{array}{l}\dot{j} \\
\dot{I}\end{array}$ & $\begin{array}{l}\tilde{i} \\
\end{array}$ & 0 & $\overrightarrow{0}$ & $=$ & $\ddot{6}$ & $\begin{array}{l}\infty \\
\vdots \\
\circ\end{array}$ & $\stackrel{\cong}{I}$ & 0 & ָั & $\stackrel{2}{I}$ & $\overrightarrow{\tilde{\gamma}}$ & $\mid \begin{array}{r}\dot{q} \\
\dot{q}\end{array}$ & $\begin{array}{l}n \\
n \\
n \\
n\end{array}$ & $\mid \begin{array}{l}0 \\
\dot{\infty} \\
\dot{\infty}\end{array}$ & $\mid \begin{array}{c}m \\
m\end{array}$ & $\stackrel{\text { ते }}{0}$ & \begin{tabular}{|l|}
0 \\
$\dot{d}$ \\
$\dot{i}$
\end{tabular} & $\overrightarrow{\dot{0}}$ & $\stackrel{?}{+}$ \\
\hline 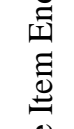 & 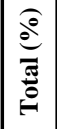 & $\begin{array}{l}\infty \\
\stackrel{j}{+}\end{array}$ & $\stackrel{F}{\stackrel{2}{*}}$ & $\stackrel{m}{\sim}$ & $\left|\begin{array}{l}\infty \\
\end{array}\right|$ & $\stackrel{ \pm}{-}$ & \begin{tabular}{|l|}
$\infty$ \\
$\stackrel{\infty}{\sim}$
\end{tabular} & $\stackrel{ \pm}{.}$ & 0 & $\overrightarrow{\dot{b}}$ & $\tilde{i}$ & in & $\stackrel{?}{\sim}$ & $\mid \begin{array}{l}\frac{0}{\infty} \\
\frac{0}{2}\end{array}$ & $\ddot{0}$ & $\grave{i}$ & $\hat{\oplus}$ & $\overrightarrow{\dot{i}}$ & $\mid \begin{array}{l}\dot{q} \\
\end{array}$ & ले & $\left|\begin{array}{l}\infty \\
\dot{+} \\
\infty\end{array}\right|$ & $\overline{\dot{m}}$ & $\begin{array}{l}+ \\
\infty \\
\infty\end{array}$ & $\frac{\stackrel{n}{m}}{m}$ & $\mid \stackrel{\dot{\vec{v}}}{\mid}$ & $\hat{i}$ \\
\hline 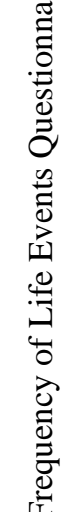 & $\Xi$ & 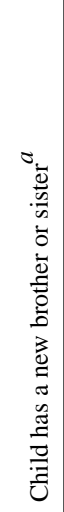 & 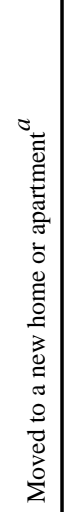 & 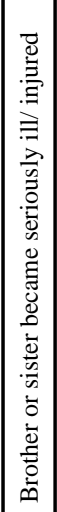 & 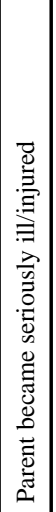 & 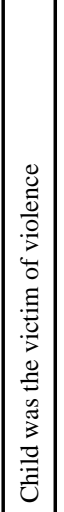 & 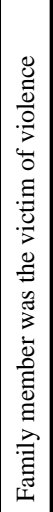 & 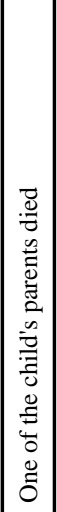 & 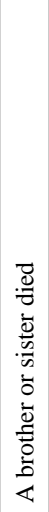 & 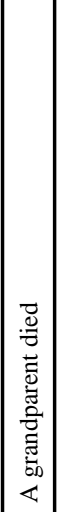 & 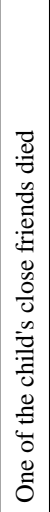 & 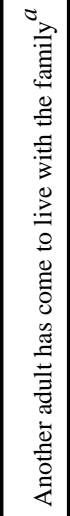 & 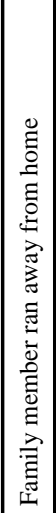 & 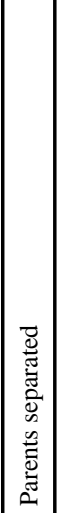 & 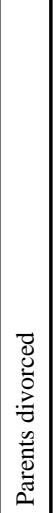 & 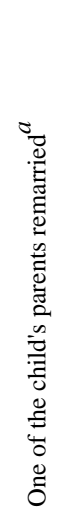 & 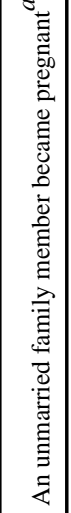 & 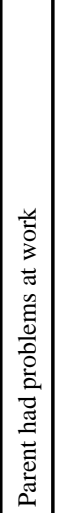 & 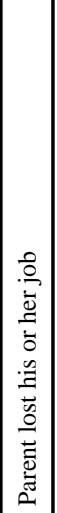 & 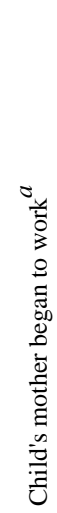 & 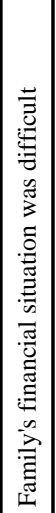 & 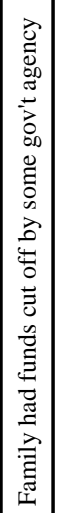 & 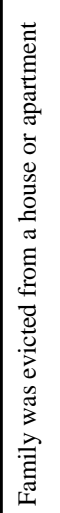 & 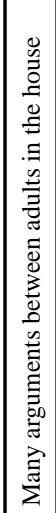 & 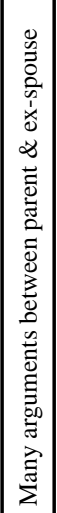 & 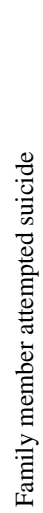 \\
\hline
\end{tabular}

Fam Relat. Author manuscript; available in PMC 2016 October 01. 

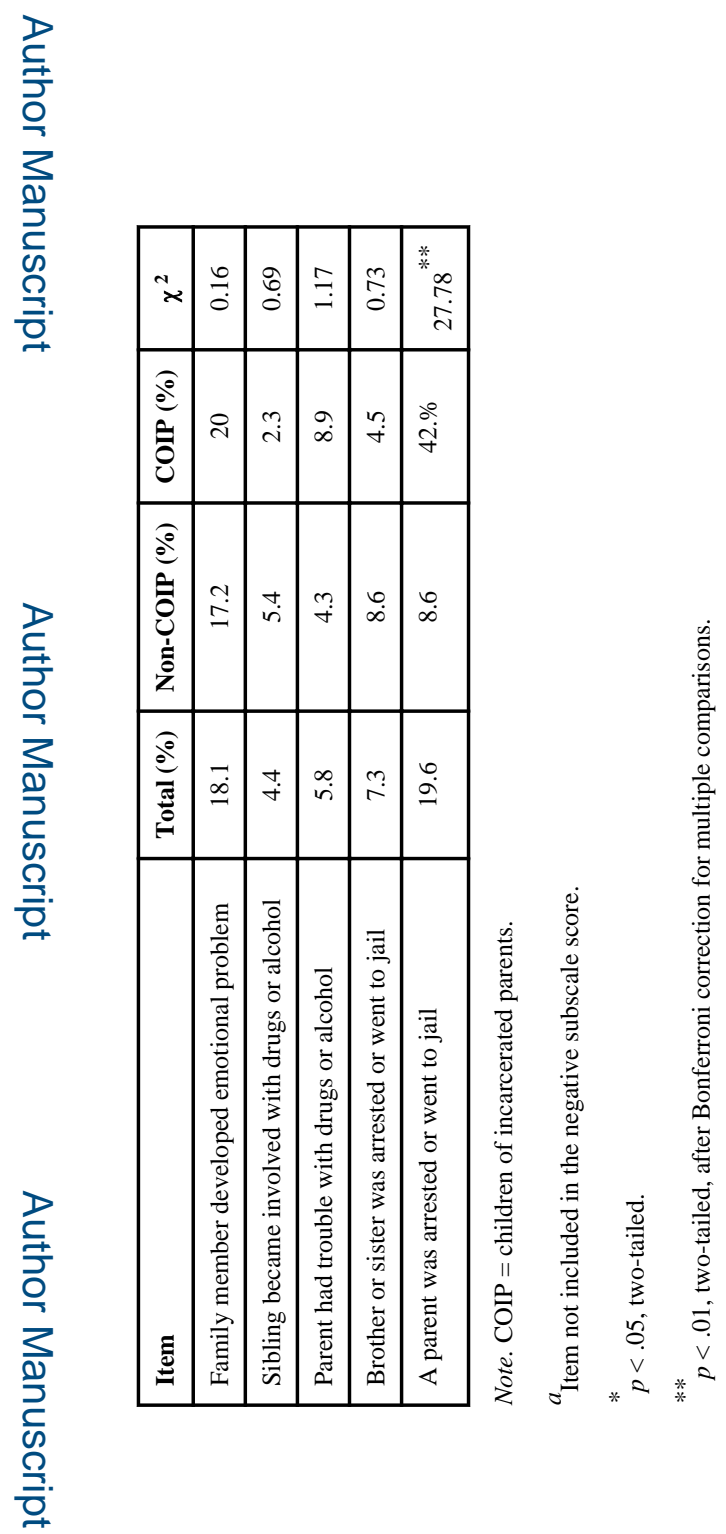

Fam Relat. Author manuscript; available in PMC 2016 October 01. 


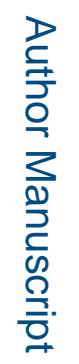

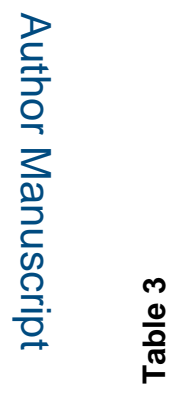

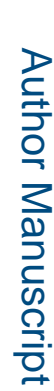

\begin{tabular}{|c|c|c|c|c|c|c|c|c|c|c|c|c|c|c|c|c|c|c|c|c|c|}
\hline 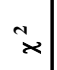 & $\stackrel{\infty}{\stackrel{\infty}{-}}$ & $\stackrel{\infty}{+}$ & $\begin{array}{l}n \\
\stackrel{n}{i} \\
\end{array}$ & $\begin{array}{l}8 \\
i \\
i n\end{array}$ & \begin{tabular}{|l|} 
\\
8 \\
0
\end{tabular} & $\stackrel{ \pm}{0}$ & 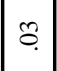 & & $\mid \begin{array}{l}8 \\
i \\
\text { in }\end{array}$ & $\tilde{o}$ & $\overrightarrow{\widehat{\jmath}}$ & $\begin{array}{c}\tilde{c} \\
\tilde{\sigma}\end{array}$ & \begin{tabular}{|l|}
$\infty$ \\
$\stackrel{\infty}{-}$ \\
\end{tabular} & 者 & $\underset{i}{\stackrel{\Delta}{i}}$ & $\left|\begin{array}{c}\infty \\
\vdots \\
0\end{array}\right|$ & $\stackrel{0}{\circ}$ & $\stackrel{\overbrace{}}{\stackrel{i}{i}}$ & $\hat{\widehat{o}}$ & $\stackrel{\infty}{\circ}$ & $\stackrel{\overbrace{}}{-}$ \\
\hline & 0 & 0 & $\mid \begin{array}{l}+ \\
\dot{J} \\
\dot{f}\end{array}$ & $\left|\begin{array}{c}\tilde{y} \\
\tilde{g}\end{array}\right|$ & 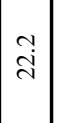 & $\begin{array}{l}\infty \\
\stackrel{\infty}{\beth}\end{array}$ & $\dot{\infty}_{\infty}$ & 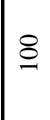 & $\exists$ & $\begin{array}{c}m \\
m\end{array}$ & $\begin{array}{l}\tilde{i} \\
\tilde{s}\end{array}$ & $\widehat{6}$ & $\hat{i}$ & $\begin{array}{l}\infty \\
\dot{m} \\
\dot{m}\end{array}$ & $\begin{array}{l}0 \\
\ddot{1}\end{array}$ & $\stackrel{\leftrightarrow}{+}$ & $\stackrel{+}{+}$ & $\stackrel{\sim}{i}$ & $\stackrel{\infty}{\infty}$ & 0 & $\partial_{\infty}$ \\
\hline
\end{tabular}

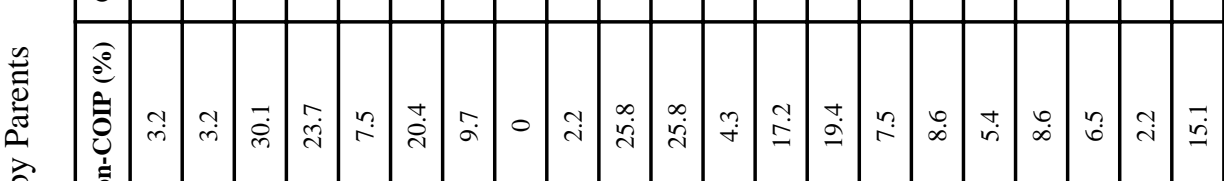

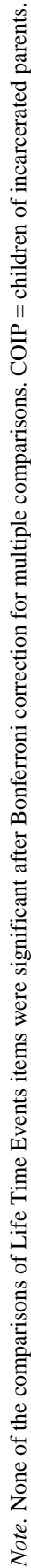

론

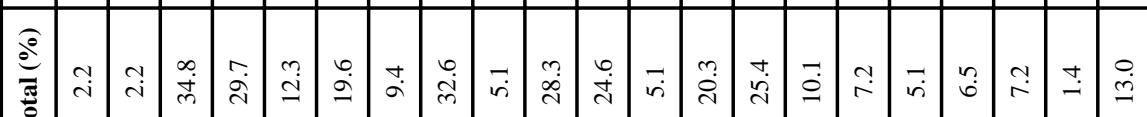

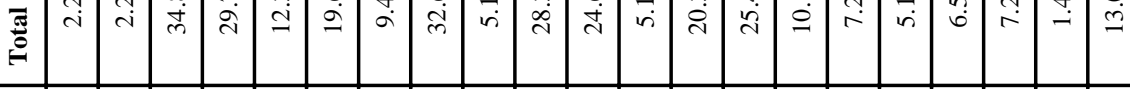

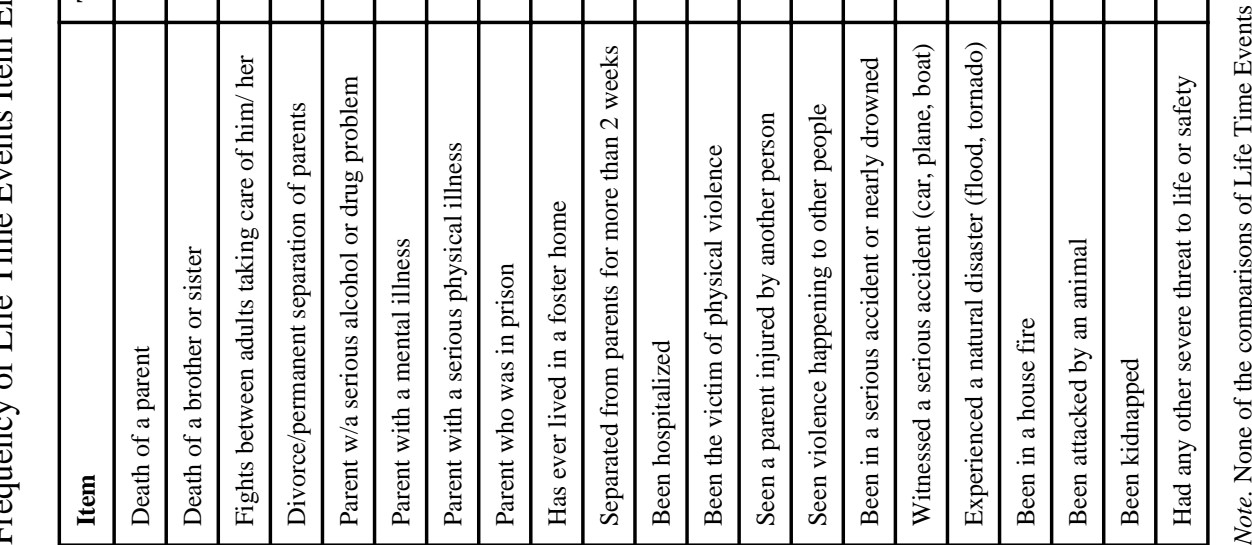

Fam Relat. Author manuscript; available in PMC 2016 October 01. 


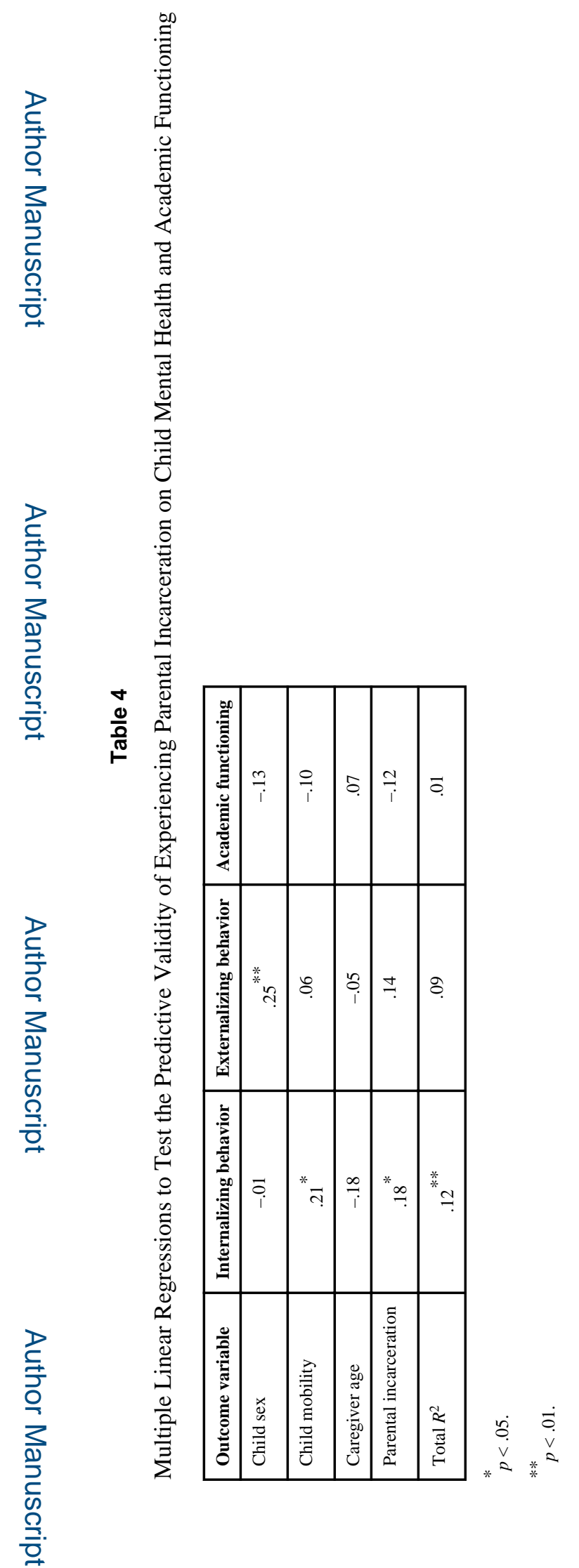

Fam Relat. Author manuscript; available in PMC 2016 October 01. 